\title{
Complete Genomics Sequencing
}

National Cancer Institute

\section{Source}

National Cancer Institute. Complete Genomics Sequencing. NCI Thesaurus. Code C146815.

A next-generation DNA sequencing service offered by Complete Genomics. Unamplified human genomic DNA is sheared into 500bp fragments and then amplified to create DNA nano-balls (DNBs). The DNBs are arrayed on a substrate and their sequence is determined by Combinatorial Probe-Anchor Ligation (CPAL) sequencing. 